Context dependency and consumer acceptance of risk reducing strategies - a choice experiment study on salmonella risks in pork

Mørkbak, Morten Raun; Christensen, Tove; Gyrd-Hansen, Dorte

Published in:

Food Research International

DOI:

10.1016/j.foodres.2011.02.020

Publication date:

2012

Document version

Peer reviewed version

Citation for published version (APA):

Mørkbak, M. R., Christensen, T., \& Gyrd-Hansen, D. (2012). Context dependency and consumer acceptance of risk reducing strategies - a choice experiment study on salmonella risks in pork. Food Research International, 45(2), 1149-1157. https://doi.org/10.1016/j.foodres.2011.02.020 


\title{
Context dependency and consumer acceptance of risk reducing strategies - a choice experiment study on Salmonella risks in pork
}

\author{
Morten Raun Mørkbak (corresponding author) \\ Institute of Food and Resource Economics, Faculty of Life Sciences, University of Copenhagen, Rolighedsvej 25, 1958 Frederiksberg C, Denmark. \\ Email: mrm@sam.sdu.dk
}

Tove Christensen

Institute of Food and Resource Economics, Faculty of Life Sciences, University of Copenhagen, Rolighedsvej 25, 1958 Frederiksberg C, Denmark. Email: tove@foi.ku.dk

Dorte Gyrd-Hansen

DSI Danish Institute for Health Services Research and Institute of Public Health, University of Southern Denmark. Winsløwsvej 9, 5000 Odense C. Email: $\underline{\text { dgh@dsi.dk }}$

\begin{abstract}
The paper investigates to what extent context dependency is present, when consumers are introduced to different risk reducing technologies and how this will affect their preferences for reductions in food risks. In particular, choice experiments are used to elicit consumer preferences for reducing Salmonella risks in pork using farm level interventions vs. decontamination of meat at the abattoir. We found an interesting asymmetry in the context dependency. The presence of the least preferred risk reduction technology (lactic acid decontamination) affected the relative preferences for the two most preferred technologies (farm level intervention relative to water decontamination). However, the presence of farm level intervention did not affect the relative preferences for the two least preferred technologies (decontamination using lactic acid relative to water). These results are in line with earlier findings of bad news having greater effect than good news - now applied to context dependency of preferences for food safety technologies.
\end{abstract}

Keywords: Economic valuation, Willingness-to-Pay, Choice experiments, Context dependence, Decontamination, Salmonella

\footnotetext{
Abbreviations: Willingness-to-Pay (WTP); Choice Experiments (CE); Lancasters Consumer Theory (LCT); Random Utility Theory (RUT); Random Parameter Logit (RPL); Alternative Specific Constant (ASC)

* The reference of the printed version is:

Mørkbak, MR, T Christensen \& D Gyrd-Hansen (2011): Context dependency and consumer acceptance of risk reducing strategies - A choice experiment study on Salmonella risks in pork. Food Research International 45: 1149-1157.

DOI:10.1016/j.foodres.2011.02.020
} 


\section{Introduction}

At a European level, Campylobacteriosis and Salmonellosis are the most frequently reported zoonotic diseases in humans with more than 320,000 confirmed cases in 2008 (EFSA, 2010). As only a smaller proportion of all cases are registered, the true number is generally believed to be up to 20 times larger (Korsgaard et al. 2005). These are large numbers and the costs to society are substantial. Denmark and most other OECD countries have implemented Salmonella control programs since the late 1980 'ies. These initiatives have reduced, but certainly not eliminated the problem. In the pursuit of further reductions, there is a growing area of research trying to improve the technological possibilities of reducing zoonotic risks in different parts of the supply chain, as well as research in assessing the economic costs of producing safer meat.

This development has opened up for a need to address attitudes, perceptions, and behavior among the general public in order to assess to what extent various risk reducing technologies are deemed acceptable and to what extent there is a willingness to pay that exceeds the costs of production. In the stated preference literature on consumer preferences for safety characteristics there is a considerable number of studies on preferences for food safety, some studies on preferences for reducing microbial risks (such as Salmonella) in meats and a few studies where preferences for the risk reducing technologies are addressed.

As a parallel development, context dependency of choice behavior has become the focus of a large literature in psychology, marketing and economics over the past three decades (Swait et al. (2002). In particular, Johnston \& Duke (2007) state that 'The omission of utility-relevant policy process attributes, for example, may generate willingness-to-pay bias related to the methodological misspecification of valuation contexts'. In the literature on consumer preferences, Korzen \& Lassen (2010a) have addressed the issue of how context affects preferences for reducing food risks, but there are (to the authors' knowledge), no studies on how context affects preferences for the technologies.

In this light, our paper provides a methodological as well as policy relevant contribution on the importance of context dependency. We examine two dimensions of context dependency. Firstly, we place people in a situation where they are asked to state their preferences for risk reduction strategies jointly with expressing preferences for reducing risks. Thereby, we are able to investigate to what extent preferences for risk reductions depend on the contexts in terms of risk reduction 
strategies. Secondly, we illustrate how preferences towards risk reduction strategies depend on what the options are. In particular, choice experiments (CE) are used to elicit consumer preferences for reducing Salmonella risks in pork using three different risk reduction technologies up through the production chain. The case study includes split samples that allow us to evaluate consumer willingness-to-pay (WTP) for a reduction in Salmonella risks when the menus of risk reduction technologies change.

The paper is organized as follows: Section 2 provides a short overview of relevant literature. Section 3 describes the Method and material used, while section 4 presents the theory of choice experiments. The results are presented in section 5, while the discussion of results and concluding remarks follows in Section 6.

\section{Other studies}

In this section, a brief overview of the literature on consumer perceptions of meat risks and technological solutions to reduce risks are presented followed by a brief presentation of the literature on the theory of context dependency.

\subsection{Valuation of food safety}

A number of studies have examined consumer preferences for reducing zoonotic risks. These studies include Goldberg \& Roosen (2007), Christensen et al. (2006), Hayes et al. (1995), and Cao et al. (2005) who focused on risk reductions in chicken; Grunert (1997), McCluskey et al. (2005), Latvala \& Kola (2003) who focused on risk reductions in beef; and Meuwissen \& van der Lans (2005) and Miller \& Unneverhr (2001), who focused on risk reductions in pork. A review of the stated preference literature for consumer preferences for foods safety (Mørkbak et al. 2009) concluded that consumers in general state a significantly positive WTP for food safety. It also concluded that the relative importance of different food safety characteristics had not been addressed systematically just as it was not possible to derive consistent evidence on the relative importance of food safety vis-à-vis other quality characteristics in meat. As a follow up study, Mørkbak et al. (2010) investigated consumer WTP for reducing Salmonella risk in pork along with the quality attributes place of origin, fat content, animal welfare, and reduced use of antimicrobial agents. They found that consumers were willing to pay for food safety but found that food safety was ranked considerably lower than fat and country of origin but more important than animal welfare. 
Other studies indicated that consumers did not find food safety an important issue in their purchase decisions - not because they were not concerned with food safety but because they considered the food they could buy as safe (Williams \& Hammitt 2000; Korzen \& Lassen. 2010a).

\subsection{Strategies to reduce food risks}

Mitchell \& McGoldrick (1996) divided consumers' risk reducing strategies in two categories: Either they could seek to reduce risk through product choice or by taking precautions after purchase. They claimed that consumers mainly try to reduce risk of product failure in the products they buy.

McCarthy and Henson (2005) assessed Irish consumers' perceived risk and their risk reducing strategies in relation to beef. They used a very broad definition of risk as risk of product failure which included risk of meat being unsafe to eat as well as risk of a lower than expected eating quality. Based on the findings in Mitchell \& McGoldrick (1996), McCarthy and Henson (2005) restricted their analysis to risk reduction strategies related to choice of product rather than strategies to minimize the consequences should a product 'fail'. They found that the level of perceived risk associated with beef was not extraordinarily high. The greatest risks perceived by respondents was financial (wasting money) followed by performance (the product will not meet taste expectations) and then safety risk. The psychological risk and social risk associated with worrying about product failure also contributed significantly to the overall perceived risk. A number of strategies to reduce risk of product failure were investigated. They are listed according to decreasing importance: Location, color, country of origin, quality marks, fat, labels, price, odor, texture, and butcher's advice. The authors stated that they would have expected safety to be the most prominent concern for consumers - not a concern about wasting money because of a quality issues. The relative low valuation of food safety is, however, in line with Mørkbak et al. (2010)

A few studies (all American) estimated WTP for risk reductions when the methods for reducing risks were explicitly mentioned. Giamalva et al. (1998) investigated the relative importance of 4 different strategies to reduce the risk of food borne diseases (HACCP, irradiation, chemical rinses, and status quo). They found that respondents clearly favored the solution using HACCP over solutions involving irradiation and chemical rinses. Other studies of consumer valuation of food risk reduction strategies have dealt with irradiation of meat (Giamalva et al. 1998; Hayes et al. 2002; Nayga et al. 2006; Shogren et al. 1999). 
Barcellos et al. (2010) conducted focus group interviews in Spain, Germany, France, and the UK on consumers' acceptance of beef processing technologies. They investigated the following seven risk reduction technologies: Marinating by injection aiming for increased healthiness, safety or eating quality; marinating by submerging aiming for increased eating quality; nutritional enhancement and restructuring through enzyme binding; shock wave treatment and finally, thermal processing. Overall, respondents supported the development of 'non-invasive' technologies that were able to provide more healthiness and better eating quality. Excessive intervention in meat production chains was severely criticized and participants expressed their longing to keep beef processing 'simple and natural'. They suggested a relationship between acceptance of new beef products, technology familiarity and perceived risks related to its application. Excessive manipulation and fear of moving away from 'natural' beef were considered negative outcomes of technological innovations. Beef processing technologies were predominantly perceived as valuable options for convenience shoppers and less demanding consumers.

Similar, a study by Siegrist (2008) on factors that influence public acceptance of innovative technologies and products in the food area suggested that perceived benefit, perceived risks and perceived naturalness were important factors for the acceptance of new food technologies. Lay people might not only have difficulties in assessing risks associated with novel food technologies, but also the benefits of such technologies. Therefore, they found that trust was important for the acceptance of new food technologies.

Korzen \& Lassen (2010b) conducted a focus-group based study where strategies to reduce zoonotic risks were investigated. They found that when people were introduced to zoonosis as a potential problem, they argued for safety strategies to handle this problem mostly at the level of consumer practices or through public control. None of the focus group participants mentioned decontamination as a risk reduction strategy and when it was introduced to the discussion, it was met with resistance. The general picture was that food should be as fresh and untreated as possible.

\subsection{Context dependency}

The traditional expected utility theory dating back to Von Neumann \& Morgenstern (1944) was based on the assumption of an expected utility function that was linear in probability but potentially non-linear in outcome. Also, utility was assumed to be independent of context and decision process. These assumptions have increasingly been questioned. In particular, the field of psychology has 
offered explanations for why choice behavior frequently has been inconsistent with expected utility theory. In prospect theory, it was found that people's choices typically were affected by reference points and that small probabilities were given too high weights while large probabilities were given too low weights (Kahneman \& Tversky 1979; Levy, 2003; Lloyd, 2003; Nelson, 2001). Furthermore as put forward by Tversky and Kahneman (1991) and subsequently analyzed in a number of stated preferences papers (Borger \& Fosgerau al. 2008; Hu et al. 2006), the marginal utility was typically a decreasing function of the size of gains as well as losses, which was not consistent with von Neumann \& Morgenstern's expected utility function. A closely related explanation, originating from the field of psychology, was the importance of context, where context refers to the current and historical setting in which a choice was offered (McFadden, 1999). The context was found to be particularly important when respondents were asked to state their preferences for uncertain alternatives because respondents would have to draw their own inferences about attributes. Bulte et al. (2005) examined the effect on consumer WTP of varying the causes of environmental problems. They found that respondents had a significantly higher WTP for solving problems that were caused by humans than when the problems were caused by nature. A similar argument has been put forward in relation to understanding why consumers seem to accept a higher level of Campylobacter risk in animal products from outdoor raised animals than from animals kept indoors (ICROFS 2008). Similarly, Bosworth et al. (2010) examined if WTP depended on whether health risk reductions were obtained using prevention or treatment mechanisms. They found that marginal utility associated with avoided deaths to be almost twice as high for prevention policies as for treatment policies. They also found significant heterogeneity with respect to disease type, the group targeted by the policy, and respondent characteristics. As the present choice experiment involves rather unfamiliar attributes in terms of risk reductions and risk reduction technologies, we suspect that the context is of particular importance.

Hayes et al. (2002) investigated the irradiation of pork products using an experimental Vickrey auction, whilst they also tested the effect of providing positive and negative information regarding the irradiation of pork products. They found that the provision of positive information resulted in higher bids, but that positive information combined with negative information had a similar effect to providing only negative information. This suggests that negative information has a greater influence on consumers than positive information, supporting the issue of loss aversion suggested in prospect theory (Kahneman \& Tversky 1979; Thaler, 1980; Tversky \& Kahneman 1991). 
Furthermore, we follow the line of Wittink et al. (1990) who was the first to document that context with respect to the number of attribute levels matters in conjoint rating and ranking studies. They found that the number of levels on which an attribute was defined had a direct impact on the resulting attribute importance. The more attribute levels, the larger marginal utilities. Wittink et al. (1990) found that even if the range was held constant, the addition of intermediate levels could increase this importance. This is a methodological problem that we need to keep in mind. Our split sample approach does not serve to solve the problem but awareness of the potential problem allows us to interpret our result accordingly.

\section{Method and material}

The values of risk reductions and of risk reduction strategies were estimated using CE. The method was found to be particularly suitable because the primary focus of the research question was on the relative weighting of the food characteristics, and on whether the presence of specific attribute levels would affect preference structures. This section first describes the design of the CE survey, followed by the econometrics and modeling of the data.

\subsection{Design}

The choice of attributes was partly fixed a priori as part of a larger policy oriented research project. Three risk reduction strategies to reduce Salmonella risk in pork were investigated: 1) risks are reduced at farm level by increasing hygiene and changing feed, 2) risk reductions are obtained at the abattoir using water/steam, 3) risk reductions are obtained at the abattoir using lactic acid.

Context dependency in terms of the presence of different reduction strategies was tested by using a split-sample design. Respondents were randomly assigned to sample A, B and C which only differed with respect to risk reduction strategies: Respondents in sample A were presented with all three strategies while respondents in sample B were presented with farm-level and water/steam strategy and sample $\mathrm{C}$ with water/steam and lactic acid (as shown in Table 1).

The 'status quo' was characterized by the prevalent Salmonella risk and the prevalent risk reduction strategy in 2005. The prevalent level of Salmonella risk was that 10 out of 1000 packages could be expected to contain Salmonella bacteria (Anonymous, 2009). The prevalent Salmonella control program involved restrictions on fodder, controls and surveillance of pig herds, and penalty schemes at abattoirs for delivering Salmonella infected pigs (Anonymous, 2009). The prevalent 
Salmonella strategy does not include any of the risk reduction strategies investigated in the CE. The potential reductions in Salmonella risk included a small reduction to 5 out of 1000 packages being infected, a medium reduction to 1 out of 1000 packages being infected and finally, an elimination of Salmonella risk. The characteristics and the associated levels that were investigated in the CE are presented in Table 1.

Table 1: Characteristics in the choice experiment

\begin{tabular}{|lll|}
\hline Characteristics & Levels & Included in the following splits \\
\hline Salmonella risk & 0 & Sample A, B, \& C \\
& 1 out of 1000 & Sample A, B, \& C \\
\hline Risk reduction strategy & farm-level 1000 & Sample A, B, \& C \\
\hline water/steam & Sample A \& B \\
\hline lactic acid & Sample A, B, \& C \\
\hline Price (DKK) & Sample A \& C \\
\hline
\end{tabular}

Note a): 1 Euro $\approx 7.45$ DKK

Prior to the design of the CE, three focus group interviews were performed. One of the aims was to find easily understandable formulations of risk reductions and risk reduction strategies. The descriptions of risk reductions and risk reduction strategies that were presented to the respondents are presented in Table 2. 
Table 2: Description of the two characteristics as presented to the respondents.

\begin{tabular}{|c|c|}
\hline Salmonella risk & Risk reduction strategies \\
\hline $\begin{array}{l}\text { In } 2005,10 \text { out of } 1000 \text { packages of minced pork were } \\
\text { infected with Salmonella in the Danish stores. } \\
\text { The risk of a Salmonella infection can be eliminated by } \\
\text { having good kitchen hygiene. Nevertheless, } \\
\text { approximately } 2500 \text { Danes were infected with } \\
\text { Salmonellosis in } 2005 \text {, which could be traced back to } \\
\text { pork meat. Usual symptoms of Salmonellosis are fever, } \\
\text { headache, nausea, vomiting, and diarrhea for duration of } \\
3-6 \text { days (on occasion weeks). In rare cases, } \\
\text { Salmonellosis can cause death. } \\
\text { Risk levels: } \\
\text { Today } 10 \text { out of } 1000 \text { packages of minced pork is infected } \\
\text { with Salmonella, hence this is also the case for the } \\
\text { packages you usual purchase. Today it is not possible to } \\
\text { purchase pork with reduced Salmonella risks but imagine } \\
\text { that it is possible. You can choose between products with } \\
\text { the following risk of containing Salmonella: } \mathbf{0} \mathbf{1} \text { out of } \\
\mathbf{1 0 0 0} \text { or } \mathbf{5} \text { out of } \mathbf{1 0 0 0 .}\end{array}$ & $\begin{array}{l}\text { Imagine that packages of minced pork are labeled with } \\
\text { the method used to reduce the Salmonella risk. There are } \\
\text { no health risks associated with the different methods. The } \\
\text { meat will maintain its usual color and taste after the } \\
\text { different treatments. } \\
\text { Risk reduction strategies: } \\
\text { The risk reduction will take place at the farm-level. The } \\
\text { amount of Salmonella bacteria is reduced in the pigs by } \\
\text { changing the feed and hygiene conditions in the pigpen. } \\
\text { The animal welfare is not affected at all. } \\
\text { The risk reduction will take place at the abattoir. The } \\
\text { amount of Salmonella bacteria is reduced in the pork by } \\
\text { sprinkling the carcasses with hot water/steam for a few } \\
\text { seconds. } \\
\text { The risk reduction will take place at the abattoir. The } \\
\text { amount of Salmonella bacteria is reduced in the pigs by } \\
\text { sprinkling the carcasses with a low concentration of lactic } \\
\text { acid for a few seconds. }\end{array}$ \\
\hline
\end{tabular}

These attributes were related to a specific pork product which was chosen (in the specific survey) to be a package of minced pork (500 g). Respondents were faced with two alternative minced pork products plus a third alternative denoted 'status quo'. In addition to being characterized by the prevalent level of Salmonella risk and the prevalent Salmonella control, the price for the status quo alternative was identified earlier in the questionnaire, as the price of the usual purchased product by the individual respondent. Hence, the respondents should choose between two hypothetical minced pork products and the minced pork product they usually purchase. Using the respondents "own" status quo values has been recommended in the literature and used in other studies to mimic the actual purchasing situation as closely as possible (Kontoleon \& Yabe 2003; Ruby et al. 1998). The 
use of individual specific status quo alternatives in the design procedure of CE has been further developed by Rose et al. (2008), in what they refer to as segment-specific efficient designs, twostage process designs and individual efficient designs. An example choice set is shown in Figure 1.

\begin{tabular}{lccc}
\hline Minced pork (500g) & Alternative A & Alternative B & Alternative C \\
\hline Salmonella risk & 5 out of 1000 & 0 out of 1000 & My usual purchase \\
Risk reduction strategy & Lactic acid & Farm-level & 80 \\
Price (DKK) & 51 & $\square$ & $\square$ \\
\hline I choose (tick the box) & $\square$ & & \\
\hline
\end{tabular}

Figure 1: Choice set example of a choice task for respondents in sample A.

By systematically combining the 3 types of risk reduction technologies, the 3 levels of Salmonella risks, and the 6 different price levels, a statistically efficient design was obtained that facilitated the identification of the individual attribute levels effect on the choice of minced pork. D-efficient fractional factorial designs were used for all three split samples, resulting in 9 choice sets that were presented to each respondent containing 2 hypothetical alternatives and a status quo alternative each.

\subsection{Sample selection}

The discrete choice experiment was conducted using an Internet panel. The sample was obtained from The Nielsen Company's online database in October 2007 to which panel members were invited to participate. Out of approximately 2.5 million private Danish households, $87 \%$ were "online". The sample consisted of individuals over the age of 18 years and living in a household with Internet access. The response rate in the survey was $31 \%$, resulting in a sample of 4180 respondents. Samples sizes were 844, 1662 and 1674 respectively. The socio-demographic distributions of the 3 samples are shown in Table 3. 
Table 3: Socio-Demographic Distribution of the Respondents in the three Samples compared to the reference population and to each other (The $\chi$ - tests in the final 5 columns $\mathrm{A}, \mathrm{B}, \mathrm{C}, \mathrm{A} / \mathrm{B}$, and $\mathrm{A} / \mathrm{C}$ represent tests of the sample frequencies relative to the frequencies in the Danish population and across samples). The intervention strategies presented in each sample are shown in parentheses.

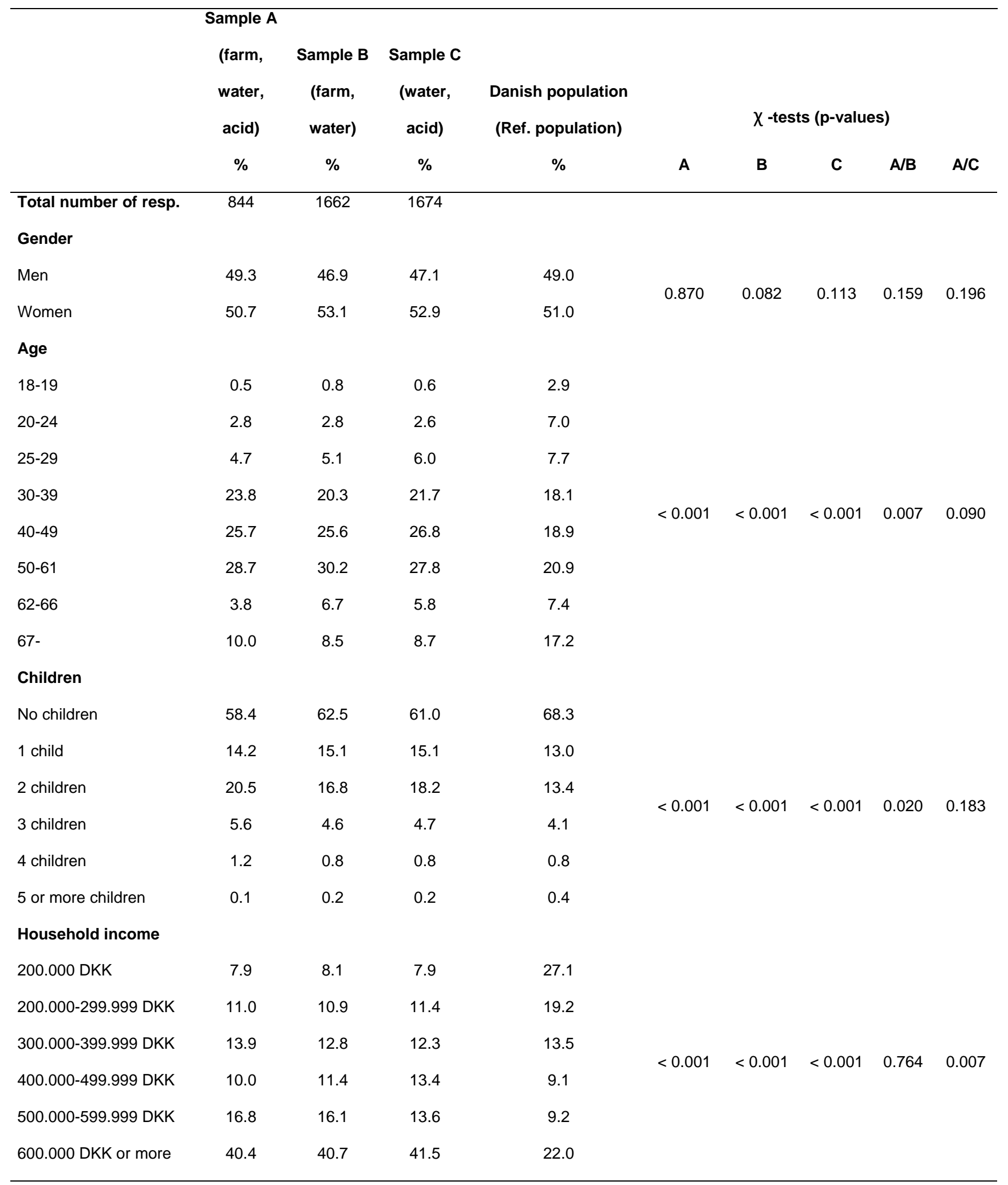


The results showed that the samples were only representative for the Danish population with respect to gender. However, when samples $\mathrm{A}$ and $\mathrm{B}$, and samples $\mathrm{A}$ and $\mathrm{C}$ were compared (chi-tests presented in the two outer right columns $\mathrm{A} / \mathrm{B}$ and $\mathrm{A} / \mathrm{C}$ ), the samples were more or less similar in their socio-demographic distributions ${ }^{1}$.

\section{Theory}

The underlying theory of CE was based on Lancaster's Consumer Theory (LCT) (Lancaster, 1966) and Random Utility Theory (RUT) (Luce, 1959; McFadden, 1974). In LCT, consumer preferences were defined in relation to bundles of characteristics and the demand for goods was a derived demand. Consumption was the activity of extracting characteristics from goods (Gravelle \& Rees 1992). According to Lancaster, the (indirect) utility that individual $i$ achieved from good $j=1, \ldots n$ $\left(V_{i j}\right)$ was the sum of the utilities obtained from each of the $K$ characteristics $s_{k i j}$ for $k=1, \ldots K$. Assuming linearity, the indirect utility of alternative $j$ for individual $i$ was:

$$
V_{i j}=\beta_{1} s_{1 i j}+\beta_{2 j} s_{2 i j}+\ldots \ldots \ldots+\beta_{K j} s_{K i j}
$$

where $s_{k i j}$ was the level of attribute $k$ in alternative $j$ faced by individual $i$, and $K$ was the number of attributes. Each attribute $s_{k}$ for $k=1, \ldots, K$, could take on $L_{k}$ possible values corresponding to the predetermined attribute levels. The parameter $\beta_{k j}$ represented the weight by which attribute $k$ in alternative $j$ was valued. For simplicity, it was assumed that the weights $\beta_{k}$ were independent of alternative $j$.

Random utility theory stated that individuals made choices according to a deterministic part that depended on the attributes of the alternative along with some degree of randomness (a random component). Allowing $U_{i j}$ to represent the utility function, $V_{i j}$ was the deterministic component and $\varepsilon_{i j}$ was the random component of the individual's choice (Hanley et al. 2002; Holmes \& Adamowicz 2003). Then individual $i$ 's utility of alternative $j$ could be written as:

$$
U_{i j}=V_{i j}+\varepsilon_{i j}
$$

\footnotetext{
1. Age, children, and income were included as explanatory variables in all models in order to control for possible impact of the imperfect randomisation (data not shown). Inclusion of these variables had no significant impact on the estimated coefficients of the remaining variables.
} 
The RUT formulation of utility in Equation (2) also corresponded with the notion that a researcher only has partial knowledge of the real structure of individuals' preferences.

The model used in this paper was a Random Parameter Logit (RPL) model, accounting for individual taste variation. Coefficients vary over decision makers in the population with the density $f(\beta)$, allowing for taste heterogeneity, rather than being fixed like in the standard logit expression. Because the researcher could not observe the $\beta_{i}$ for each individual $\mathrm{s}($ he) could not condition on $\beta$. Hence, the unconditional choice probability was the integral of the conditional probability on $\beta_{i}$ over all possible variables of $\beta_{i}$ :

$P_{i j}=\int\left(\frac{e^{\beta S_{i j}}}{\sum_{n} e^{\beta S_{i n}}}\right) f(\beta) d \beta$

The distributions of the coefficients have often been specified as either being normally or lognormally distributed. The log-normal distribution has often been used when the coefficient has been known to have the same sign for every individual, such as the cost coefficient that is expected to be negative for all individuals (Train 2003). In the present paper, the non-price attributes were assumed to follow normal distributions. The price attribute was assumed constant which allowed a straight forward estimation of the distribution of WTP.

Since the utility function was assumed to be linear in price, the marginal WTP for the attribute was the ratio between the parameter of the attribute and the cost parameter in the utility function (1), such that:

$W T P=-\frac{\text { Attributeparameter }}{\text { Costparameter }}$

The reader should have in mind that the estimated WTP in the present study are marginal welfare estimates. These values can only be interpreted as welfare estimates assuming that the intervention will be chosen with certainty, and that introduction of a new decontamination method does not impact on the quantity of pork demanded (see Lancsar and Savage 2004 for a detailed discussion on the deviation of welfare estimates). 
Each respondent answered 9 different choice sets which allow us to use the panel structure of the data when estimating the models allowing coefficients to vary over people but to be constant over choice situations for each respondent (Train 2003).

\section{Results}

The results of the estimated main effect models are presented in Table 4 for all three split samples (A, B, and C). Decontamination with water has been used as the base level because water was the only risk reduction strategy that was present in all 3 samples.

Table 4: RPL models for sample A, B, and C. The intervention strategies presented in each sample are shown in parentheses.

\begin{tabular}{|c|c|c|c|c|c|c|c|}
\hline \multirow[b]{3}{*}{ Attribute } & & \multirow{2}{*}{\multicolumn{2}{|c|}{$\begin{array}{c}\text { Sample A } \\
\text { (farm, water, acid) }\end{array}$}} & \multirow{2}{*}{\multicolumn{2}{|c|}{$\begin{array}{c}\text { Sample B } \\
\text { (farm, water) }\end{array}$}} & \multirow{2}{*}{\multicolumn{2}{|c|}{$\begin{array}{c}\text { Sample C } \\
\text { (water, acid) }\end{array}$}} \\
\hline & & & & & & & \\
\hline & & Coefficient & Std.err. & Coefficient & Std.err. & Coefficient & Std.err. \\
\hline $\begin{array}{l}\text { Base intervention }(\mathrm{ASC})^{\mathrm{a})} \text { : } \\
\text { Risk reduction using water } \\
\text { decontamination \& a }\end{array}$ & Mean & -2.6035 & 0.1505 & -1.9202 & 0.0948 & -2.1167 & 0.1057 \\
\hline $\begin{array}{l}\text { Salmonella risk of } 5 \text { out of } \\
1000\end{array}$ & Std. Dev. & 2.7606 & 0.1171 & 3.0958 & 0.0956 & 3.4414 & 0.1086 \\
\hline \multirow{2}{*}{$\begin{array}{l}\text { Salmonella risk: elimination } \\
\text { instead of } 5 \text { out of } 1000 \\
\text { packages being infected }\end{array}$} & Mean & 2.3934 & 0.1053 & 1.9334 & 0.0712 & 1.8698 & 0.0761 \\
\hline & Std. Dev. & 0.8242 & 0.1020 & 1.5337 & 0.0769 & 1.4959 & 0.0820 \\
\hline \multirow{2}{*}{$\begin{array}{l}\text { Salmonella risk: } 1 \text { out of } \\
1000 \text { instead of } 5 \text { out of } \\
1000 \text { packages being }^{\text {infected }} \text { () }\end{array}$} & Mean & 1.4548 & 0.0989 & 1.2622 & 0.0594 & 1.2093 & 0.0631 \\
\hline & Std. Dev. & 0.0157 & 0.1528 & 0.7733 & 0.0944 & 0.5742 & 0.1118 \\
\hline \multirow{2}{*}{$\begin{array}{l}\text { Risk reduction at farm level } \\
\text { instead of using } \\
\text { water/steam }\end{array}$} & Mean & 0.9901 & 0.0908 & 0.3220 & 0.0560 & & \\
\hline & Std. Dev. & 1.2407 & 0.1035 & 1.4923 & 0.0664 & & \\
\hline \multirow{2}{*}{$\begin{array}{l}\text { Risk reduction using Lactic } \\
\text { acid decontamination } \\
\text { instead of using } \\
\text { water/steam c) }\end{array}$} & Mean & -0.9318 & 0.1172 & & & -1.0713 & 0.0667 \\
\hline & Std. Dev. & 1.1572 & 0.1348 & & & 1.5052 & 0.0773 \\
\hline
\end{tabular}




\begin{tabular}{lcccccc} 
Price & -0.0852 & 0.0024 & -0.0890 & 0.0018 & -0.0975 & 0.0020 \\
\hline $\mathrm{LRI}^{\mathrm{b})}$ & & & & & & 0.4853 \\
Log L & 0.4629 & 0.4135 & & \\
& -4482 & -9639 & & -8519 & \\
\hline
\end{tabular}

Note: a) The coefficient for ASC captures the marginal utility of the base intervention relative to the status quo product. The coefficients of the other attributes are defined relative to the base intervention. Hence, the coefficients for the other attributes have to be added to the value of the base intervention characteristic to interpret them relative to the status quo. b) LRI refers to the Likelihood Ratio Index presented by Louviere et al. (2000). c) The within column results 'elimination' vs. 1 out of a 1000' and 'farm-level' vs. lactic acid' have been tested against each other through a t-test. The test results are not presented, but there were highly significant differences between the respective attribute levels.

The overall picture of the estimations indicated that respondents on average had positive preferences for reducing Salmonella risks, and that risk elimination was preferred over risk reduction. We also found that an average respondent preferred farm level intervention over risk reduction using water/steam, and preferred using water/steam over using lactic acid. These results are shown in Table 4. Further details of the results for sample A can be found in Mørkbak et al. (2011).

An alternative specific constant (ASC) was included in all three models. The ASC has often been interpreted as capturing the value of choosing a hypothetical alternative (the base intervention alternative) relative to choosing the status quo (see for example Adamowicz et al. (1998)). Parameter values were estimated relative to a base level which was chosen to be a small risk reduction and decontamination using water which we denote as the base level intervention. As a consequence, preferences for a small risk reduction and for using water/steam decontamination were only captured as a combined value in the ASC coefficient. Hence, additional assumptions on preferences were needed in order to separate preferences for water decontamination relative to prevalent Salmonella policy and preferences for small risk reduction relative to the base-line risk level.

In all three models, large negative values of the ASC-coefficient were found, which indicated that respondents very strongly preferred the status quo compared to the base intervention. We assumed that this strong preference for keeping the status quo most likely was the net-effect of strong negative preferences for risk reduction using water combined with small positive preferences for reducing risks. Using this assumption, we concluded that an average respondent had the following 
ranking of risk reduction strategies in sample A: The present policy was the most preferred risk reduction strategy followed by farm level reductions, decontamination using water and finally decontamination using lactic acid. This ranking was robust across all samples (the reduction strategies lactic acid and farm-level intervention were excluded from sample B and C respectively, so nothing can be said about how these are ranked in the two respective samples).

In short, the current Salmonella policy was preferred over all types of risk reducing methods. And (as follows intuition), all levels of risk reductions compared to the present risk level were preferred when consumers were only focusing on risk reductions. We were consequently dealing with a situation involving (for all samples A, B and C) trade-offs between risk reduction and mode of risk reduction.

As another important general observation, the estimates of standard deviations that allow for individual tastes revealed that respondents had heterogeneous preferences for some of the attributes including the price parameter. Furthermore, the log-likelihood ratio index (LRI) indicates that all models provide a good fit to the data with values between 0.4135 and 0.4853 (Louviere et al. 2000).

The issue of whether context affected marginal rates of substitution (i.e. the relative weighting of attributes and attribute levels) was addressed by comparing model A with models B and C, respectively. To this end, preferences were expressed as WTP estimates for individual attribute levels. The WTP estimates in samples B and C were each compared with WTP estimates in sample A. Means and variances of the WTP's were estimated using the Krinsky-Robb's method (Krinsky \& Robb 1986), with 2000 replications (see Table 5). In order to test whether the WTP estimates were significantly affected across sample splits we applied a t-test.

Within each column of Table 5, WTP values for different combinations of risk reductions and risk reduction strategies can be added in order to estimate the overall WTP for a given intervention (an intervention is defined as a combination of risk reduction and risk reduction method) relative to the base intervention. This practice hinges on the assumption of additive utility function and will be discussed in the concluding section of the paper. Furthermore, it is implicitly assumed that a given risk reduction method is introduced as a general rule across the whole pork industry, so that we can assume that the given alternative is chosen with certainty (for a discussion of scenarios where this may not be true see Lancsar \& Savage (2004)). 
Table 5: WTP estimates for sample A, B, and C along with p-values from the T-test. The intervention strategies presented to each sample are shown in parentheses.

\begin{tabular}{|c|c|c|c|c|c|}
\hline & $\begin{array}{c}\text { Sample A } \\
\text { (farm, water, acid) }\end{array}$ & $\begin{array}{c}\text { Sample B } \\
\text { (farm, water) }\end{array}$ & $\begin{array}{l}\text { Sample C } \\
\text { (water, acid) }\end{array}$ & $A$ vs $B$ & A vs $C$ \\
\hline & WTP $^{\mathrm{a})}$ & WTP ${ }^{\text {a) }}$ & WTP $^{\mathrm{a})}$ & T-test & T-test \\
\hline Attribute & $(\operatorname{var}(W T P))$ & $(\operatorname{var}(W T P))$ & $(\operatorname{var}(W T P))$ & (p-values) & (p-values) \\
\hline \multirow{2}{*}{$\begin{array}{l}\text { Base intervention (ASC): Risk } \\
\text { reduction using water decontamination } \\
\& \text { a Salmonella risk of } 5 \text { out of } 1000\end{array}$} & -30.55 & -21.58 & -21.71 & $<0.001$ & $<0.001$ \\
\hline & (3.20) & $(1.12)$ & $(1.17)$ & & \\
\hline \multirow{2}{*}{$\begin{array}{l}\text { Salmonella risk: elimination instead of } \\
5 \text { out of } 1000 \text { packages being } \\
\text { infected }^{\text {b) }}\end{array}$} & 28.09 & 21.72 & 19.18 & $<0.001$ & $<0.001$ \\
\hline & $(1.47)$ & $(0.56)$ & $(0.52)$ & & \\
\hline \multirow{2}{*}{$\begin{array}{l}\text { Salmonella risk: } 1 \text { out of } 1000 \text { instead } \\
\text { of } 5 \text { out of } 1000 \text { packages being } \\
\text { infected }{ }^{b)}\end{array}$} & 17.07 & 14.18 & 12.40 & 0.0253 & $<0.001$ \\
\hline & $(1.24)$ & $(0.42)$ & $(0.38)$ & & \\
\hline \multirow{2}{*}{$\begin{array}{l}\text { Risk reduction at farm level instead of } \\
\left.\text { using water/steam }{ }^{b}\right)\end{array}$} & 11.62 & 3.62 & & $<0.001$ & \\
\hline & $(1.15)$ & (0.39) & & & \\
\hline \multirow{2}{*}{$\begin{array}{l}\text { Risk reduction using Lactic acid } \\
\text { decontamination instead of using } \\
\text { water/steam }^{\text {b) }}\end{array}$} & -10.93 & & -10.99 & & 0.9721 \\
\hline & $(1.85)$ & & $(0.44)$ & & \\
\hline \multicolumn{6}{|l|}{ Standard deviations } \\
\hline \multirow{2}{*}{$\begin{array}{l}\text { Base intervention (ASC): Risk } \\
\text { reduction using water decontamination } \\
\& \text { a Salmonella risk of } 5 \text { out of } 1000\end{array}$} & 32.40 & 34.79 & 35.30 & 0.1600 & 0.0910 \\
\hline & (1.78) & $(1.11)$ & $(1.16)$ & & \\
\hline \multirow{2}{*}{$\begin{array}{l}\text { Salmonella risk: elimination instead of } \\
5 \text { out of } 1000 \text { packages being infected }\end{array}$} & 9.67 & 17.23 & 15.34 & $<0.001$ & $<0.001$ \\
\hline & (1.28) & $(0.60)$ & $(0.57)$ & & \\
\hline \multirow{2}{*}{$\begin{array}{l}\text { Salmonella risk: } 1 \text { out of } 1000 \text { instead } \\
\text { of } 5 \text { out of } 1000 \text { packages being } \\
\text { infected }\end{array}$} & 0.18 & 8.69 & 5.89 & $<0.001$ & 0.0087 \\
\hline & (3.28) & $(1.01)$ & $(1.44)$ & & \\
\hline \multirow{2}{*}{$\begin{array}{l}\text { Risk reduction at farm level instead of } \\
\text { using water/steam }\end{array}$} & 14.56 & 16.77 & & 0.1324 & \\
\hline & (1.27) & $(0.88)$ & & & \\
\hline \multirow{2}{*}{$\begin{array}{l}\text { Risk reduction using Lactic acid } \\
\text { decontamination instead of using } \\
\text { water/steam }\end{array}$} & 13.58 & & 15.44 & & 0.2840 \\
\hline & (2.47) & & $(0.54)$ & & \\
\hline
\end{tabular}


Note: a) The WTP estimates are presented in DKK, and represent the amount the consumers will pay extra for 500g of minced pork with the given characteristics (1 Euro equals 7.45 DKK). The WTP for the ASC captures the willingnessto-pay for the base intervention relative to the status quo product. The WTP for the other attributes are defined relative to the base intervention. Hence, the WTP for the other attributes have to be added to the WTP for the base intervention characteristic to interpret them relative to the status quo. b) The within column results 'elimination' vs. 1 out of a 1000' and 'farm-level' vs. lactic acid' have been tested against each other through a t-test. The test results are not presented, but there were highly significant differences between the given attribute levels.

First, we investigated whether the presence of lactic acid affected preferences for reducing risk at farm level (sample A vs. Sample B). Hence, we analyzed the importance of the presence of 'the worst' risk reduction strategy. We found that, mean WTP for farm level risk reductions was reduced significantly from 11.62 DKK (sample A) to 3.62 DKK (sample B) when lactic acid was not included as an option. Put differently, farm level risk reduction became more attractive relative to water decontamination if lactic acid was also an option.

The same picture was not found when investigating whether preferences for lactic acid relative to water decontamination were affected by the presence of farm level risk reduction (sample A vs. sample C). Using a parallel scenario description as above, we analyzed how the presence of a 'less bad' risk reduction strategy affected the relation between the two decontamination methods. We found that consumers' preferences for lactic acid were not affected by the presence of farm level risk reduction. In particular, in model $\mathrm{A}$ as well as $\mathrm{C}$, the WTP for lactic acid was 11 DKK lower than for water decontamination (10.93 DKK and 10.99 DKK respectively).

Interestingly, our results indicated that WTP for reducing risks per se was lower when the number of risk reduction strategies was reduced - regardless of whether farm level or lactic acid was removed as risk reduction options. In particular, the valuation of risk elimination decreased from 28.09 DKK (model A) to 21.72 DKK (sample B)/19.18 DKK (sample C) and the value of risk reduction decreased from 17.07 DKK (model A) to 14.18 DKK (sample B)/12.40 DKK (sample C). Furthermore, the results indicated that when either of the two reduction strategies, farm or lactic acid, were removed, the taste variation (the heterogeneity) in the samples increased statistical significantly for both levels of risk reductions. Hence, the variation in respondents' preferences for a risk reduction increased when fewer risk reduction technologies were available. 
Our results also indicated that an average respondent became less skeptical towards small risk reductions using water decontamination (the ASC) when only two risk reduction strategies were available - regardless of whether farm or lactic acid were present. In both cases, reducing the number of risk reduction strategies from three to two, the reluctance of using water decontamination to obtain a small risk reduction reduced from -30.55 DKK (model A) to -21.58 DKK in model B and -21.71 in model C.

\section{Discussion and conclusion}

The paper addressed the issue of context dependency and risk perception in consumer food choices. More specifically, we investigated to what extent the availability of different risk reduction strategies affect consumers' preferences for these strategies - and to what extent it affected their WTP for reducing Salmonella risks in pork.

First, we found that consumers were willing to pay for risk reductions. In particular, we found that consumers were able to distinguish between different risk levels and that they placed statistically significant higher values on large reductions than on small reductions. This result demonstrates sensitivity to scope with regard to risk reduction strategies and demonstrates that respondent preferences are consistent with ex ante expectations. The relative magnitudes of WTP values do clearly not pass the proportionality test, as the WTP for elimination of risk is disproportionately high. Such preferences have been observed in prior studies and are in accordance with results by Nakayachi (2000) and Fetherstonhaugh et al (1997) who suggest that such a preference pattern may be steered by a motivation to 'eliminate' risk.

That consumers truly should be willing to pay for risk reductions in the context of food has sometimes been questioned by marketing managers as well as sociologists due to the very limited market shares of Salmonella free animal products (Christensen et al. 2009). Marketing managers have suggested that differences between stated and actual behavior were of methodological nature in terms of hypothetical bias, whereas sociologists questioned the meaningfulness of assuming rational utility optimizing consumers. A new line of argument in terms of context dependency of people's perceptions of risks in meat products was suggested in Korzen \& Lassen (2010a). They found that meat safety was not an issue at all when people talked about the meat they buy and eat. This was identified as an everyday context. Only when people talked about meat production (that is, the context changed), then food safety was mentioned - and not even as an important issue in this 
context either. According to this argument, the strictly positive preferences for risk reductions that have been observed in choice experiments may therefore indicate that respondents do not consider themselves to be in an everyday consumer context when they participate in the experiment. Unfortunately we do not have data on risk perception in the present study, so disentangling the effects of our context effects on risk perception versus risk preferences are not possible.

Second, we found that prevalent Salmonella policy and risk level was preferred over farm level intervention, water decontamination, and lactic acid decontamination (in that order). In fact, for all split samples, only an intervention at farm level that eliminated risk completely was preferred to the prevalent Salmonella policy and risk level (this intervention resulted in $-30.55+28.09+11.62=9.16$ DKK in model A and $-21.58+21.72+3.62=3.76$ DKK in sample B). This result is very much in line with earlier findings of people being skeptical towards technological solutions in food production. Also, that farm level intervention was considered to be the least bad strategy is in line with earlier studies where naturalness has been found to be a desirable characteristic (Siegrist, 2008). The reluctance to accept risk reduction strategies can also be linked to the general perception that Salmonella risk was not considered to cause a problem (Korzen \& Lassen 2010a, Williams \& Hammitt 2000) and as a consequence there was no need to implement any risk reducing strategies. Altogether, our results indicate that whether an average person places a positive value on risk reduction depends on the risk reducing technology that is used. Thereby, we have identified a new type of context dependency- namely that preferences for risk reductions depend on how they are obtained.

Third, we found that perceptions (as measured by WTP) of risk reducing strategies to some extent depend on the availability of other strategies. We found that when risk reduction with lactic acid was mentioned as a possible risk reduction strategy, the WTP estimates for risk reduction at farm level relative to using water decontamination increased significantly. However, when risk reduction at farm level was mentioned as a possible risk reduction strategy, the relative preferences between the decontamination strategies (water and acid) were unchanged. Hence, we found an interesting asymmetry in the context dependency. A possible explanation of the asymmetric effects links to the asymmetry between comparing farm level risk reduction with two types of decontamination at the abattoir. Along these lines, we suggest that the presence of a 'preferred' farm level risk reduction strategy does not alter the perceived difference between two decontamination methods. A related explanation is the asymmetry between good and bad news. Several studies have identified a 
stronger effect of negative information than of positive (e.g. Fox et al. 2002; Hayes et al. 2002). Following this lead, the presence of a relatively 'good' risk reduction strategy (farm level intervention) does not have the same effect as the presence of a relatively 'bad' alternative (lactic acid). This effect of negative information having larger effect than positive information also corresponds to the type of loss aversion behavior stated by prospect theory (Kahneman \& Tversky, 1979; Thaler, 1980).

Wittink et al. (1990) found that the number of levels on which an attribute was defined had a direct impact on the resulting attribute importance in conjoint analyses using ratings and rankings rather than choice experiments. For all attribute levels - except decontamination using lactic acid instead of water, our results confirm this observation. A follow up study on these issues would certainly serve to fill out an information gap that is useful in communicating risk and risk reduction strategies.

Our results suggest that not only preferences for risk reduction strategies might be affected by the available spectra of risk reduction strategies, but also preferences for risk reduction per se. The observation that WTP for reducing risks was lower when the number of risk reduction strategies was reduced is not easily interpretable in relation to the sparse literature on consumer perceptions of food risks and technology. A possible explanation could be offered using results from the context of health care. Norinder et al. 2001, and Andersson \& Holm, 1998 suggest that people may prefer commodities that are (or at least appear to be) transparent, to those that are not. If respondents perceive greater variety in risk reduction technologies to be a more transparent choice-environment, then the notion of perceived comprehensibility and transparency of the intervention might explain the increased valuation of the outcomes generated as suggested by Norinder et al. (2001) and Andersson \& Holm (1998). A more straight forward interpretation of our results using the assumption of additive utility indicates that the respondents weigh the utility of reduction in the objective risk associated with buying pork that is infected with Salmonella against the disutility of different risk reduction methods. However, it is also possible that the subjective risks that respondents associate with a proposed reduction in objective risk are themselves affected by the presence of different risk reduction methods. In the present study, it is not possible to distinguish between risk perception and the preferences for reducing risks. That there is a long and winding road from objective risk to subjective risk assessment has been investigated by several authors, see e.g. Munroe \& Hanley (1999) and Teisl \& Roe (2010). Whether or not the discovered results in the 
present paper are caused by respondents preferring transparent commodities or by different contexts affecting subjective probabilities is hard to say. Shedding lights on how to increase perceived transparency in policy decisions relating to food safety as well as other areas - and how transparency affects consumers' decisions are indeed important inputs to policy making.

The advantage of the chosen method, CE, is clearly that it in a very systematic way facilitates identification of trade-offs between risk reduction and risk reduction strategies - and it enables us to estimate monetary values in terms of WTP for different combinations of risk reduction and risk reduction strategies without directly asking the respondents to state their WTP. At the same time, there is an obvious limit in the survey approach as it allows identification of what people state they do but not whether they actually do it nor why they do it. Hence, as this discussion clearly shows, the complex issue of consumer preferences for risk and ways to mitigate it certainly has benefited from a multi-disciplinary approach and increased corporation between different fields of science can only be recommended.

Our study has contributed to highlight the importance of context dependency of attitudes, perceptions and decisions. This observation does not only apply to hypothetical settings where contexts- at least to some extent - can be controlled. It also applies to observations of actual behavior where the context is typically less well described.

\section{References}

Adamowicz, W. L., Boxall, P., Williams, M., \& Louviere, J. (1998). Stated Preference Approaches for Measuring Passive Use Values: Choice Experiments and Contingent Valuation. American Journal of Agricultural Economics 80:64-75.

Andersson, F., \& Holm H.J. (1998). Transparency preference and economic behaviour, Journal of economic Behavior \& Organization 37: 349-356.

Anonymous (2009). Annual Report on Zoonoses in Denmark 2009. Danish Zoonosis Centre, The Danish Institute for Food and Veterinary Research, Ministry of Family and Consumers Affairs.

Barcellos, M. D., Kügler, J. O., Grunert, K. G., Van Wezemael, L., Pérez-Cueto, F. J. A., \& Ueland, Ø., (2010). European consumers' acceptance of beef processing technologies: A focus group study. Innovative Food Science and Emerging Technologies, 11(4), 721-732, 2010.

Borger, B., \& Fosgerau, M. (2008). The trade-off between money and time: A test of the theory of reference-dependent preferences. Journal of Urban Economics 64(1):101-115.

Bosworth, R., Cameron, T. A., \& DeShazo, J. R. (2010). Is an Ounce of Prevention Worth a Pound of Cure? Comparing Demand for Public Prevention and Treatment Policies. Medical Decision Making 30(4):40-56. 
Bulte, E., Gerking, S., List, J. A., \& Zeeuw, A. (2005). The effect of varying the causes of environmental problems on stated WTP values: evidence from a field study. Journal of Environmental Economics and Management 49:330-342.

Cao, K., Gibson, J., \& Scrimgeour, F. G. (2005). An experimental approach to estimating willingness-to-pay for improvements in food safety. 2005. 49th AARES Conference, Coffs Harbour, Australia; 9-11 February.

Christensen, T., Denver, S., Jensen,J.D., Rosenquist, H., Wingstrand, A., Aabo,S., \& Ifversen, B. (2009). Consumptions patterns and consumer risks - an overview of the Danish markets for pork, chicken, and eggs and the consumer risk associated with Salmonella and Campylobacter. No. 202 Institute of Food and Resource Economics, University of Copenhagen.

Christensen, T., Mørkbak, M., Hasler, B., Lundhede, T., Porsbo, L. J., \& Christoffersen, L. B. (2006). Information, risk perception and consumer bahaviour - a choice experiment on food safety and animal welfare. No. 180. Institute of Food and Resource Economics, KVL, Copenhagen.

EFSA (2010). The Community Summary Report on Trends and Sources of Zoonoses, Zoonotic Agents and Food-borne Outbreaks in the European Union in 2008, EFSA Journal; 2010 8(1):1496. http://www.efsa.europa.eu/en/scdocs/doc/1496.pdf

Fetherstonhaugh, D., Slovic, P., Johnson, S.M., \& Friedrich, J. (1997). Insensitivity to the value of human life: a study of psychophysical numbing. Journal of Risk Uncertainty 14:283-300.

Fox, J., Hayes, D. J., \& Shogren, J. F. (2002). Consumer Preferences for Food Irradiation: How Favorable and Unfavarable Descriptions Affect Preferences for Irradiated Pork in Experimental Auction. Journal of Risk and Uncertainty 24(1):75-95.

Giamalva, J. N., Redfern, M., \& Bailey, W. C. (1998). Dietitians employed by health care facilities preferred a HACCP system over irradiation or chemical rinses for reducing risk of foodborne disease. Journal of the American Dietetic Association 98(8):885-888.

Goldberg, I., \& Roosen, J. (2007). Scope insensitivity in health risk reduction studies: A comparison of choice experiments and the contingent valuation method for valuing safer food. Journal of Risk and Uncertainty 34:123-144.

Gravelle, H., \& Rees, R. (1992). Microeconomics. Harlow, England: Pearson Education Ltd.

Grunert, K. (1997). What's in a steak? A cross-cultural study on the quality perception of beef. Food Quality and Preference, 8:548-560.

Hanley, N., Wright, R. E., \& Koop, G. (2002). Modelling Recreation Demand Using Choice Experiments: Climbing in Scotland. Environmental and Resource Economics 22:449-466.

Hayes, D. J., Fox, J., \& Shogren, J. F. (2002). Experts and activists: how information affects the demand for food irradiation. Food Policy 27:185-193.

Hayes, D. J., Shogren, J. F., Shin, S. Y., \& Kliebenstein, J. B. (1995). Valuing Food Safety in Experimental Auction Markets. American Journal of Agricultural Economics 77(1):40-53.

Holmes, T., \& Adamowicz, W. L. (2003). Attribute Based Methods. In A Primer on the Economic Valuation of the Environment. Kluwer. 
Hu, W., Adamowicz, W. L., \& Veeman, M. (2006). Labelling Context and Reference Point Effects in Models of Food Attribute Demand. American Journal of Agricultural Economics 88(4):10341049.

ICROFS (2008). Development, growth, and integrity in the Danish organic sector - A knowledge synthesis on the opportunities and barriers for a continued development and market-based growth in production, processing, and sale of organic products. October 2008, International Centre for Research in Organic Food Systems (ICROFS).

Johnston, R. J., \& Duke, J. M. (2007). Willingness to Pay for Agricultural Land Preservation and Policy Process Attributes: Does the Method Matter? American Journal of Agricultural Economics 89(4):1098-1115.

Kahneman, D., \& Tversky, A. (1979). Prospect Theory: An Analysis of Decision under Risk. Econometrica 47(2):263-292.

Kontoleon, A., \& Yabe, M. (2003). Assessing the Impacts of Alternative 'Opt-out' Formats in Choice Experiment Studies: Consumer Preferences for Genetically Modified Content and Production Information in Food. Journal of Agricultural Policy Research 5:1-43.

Korsgaard, H., Wegner, H. C., \& Helms, M. (2005). Samfundsomkostninger forbundet med zoonotiske Salmonella- og andre fødevarebårne bakterielle infektioner i Danmark. Ugeskrift for laeger februar:760-763.

Korzen, S., \& Lassen, J. (2010a). Meat in context. On the relation between perceptions and contexts Appetite 54:274-281

Korzen, S., \& Lassen, J. (2010b). Pure Meat - Public perceptions of risk reduction strategies in meat production. Food Policy (in press).

Krinsky, I., \& Robb, A. L. (1986). On Approximating the Statistical Properties of Elasticities. The Review of Economics and Statistics 68(4):715-719.

Lancaster, K. J. (1966). A New Approach to Consumer Theory. The Journal of Political Economy $74(2): 132-157$.

Latvala, T., \& Kola, J. (2003). Impact of Information on the Demand for Credence Characteristics. International Food and Agribusiness Management Review 5(2).

Levy, J. S. (2003). Applications of prospect theory to political science. Synthese 135:215-241.

Lloyd, A. J. (2003). Threats to the estimation of benefit: are preference elicitation methods accurate? Health Economics 12:393-402.

Louviere, J., Hensher, D. A., \& Swait, J. (2000). Stated Choice Methods. Analysis and Applications. Cambridge, UK: University Press.

Luce, R. D. (1959). Individual choice behaviour. New York: Wiley.

McCarthy, M., \& Henson, S. (2005). Perceived risk and risk reduction strategies in the choice of beef by Irish consumers. Food Quality and Preference, 16:435-445.

McCluskey, J. J., Grimsrud, K. M., Ouchi, H., \& Wahl, T. I. (2005). Bovine spongiform 
encephalopathy in Japan: consumers' food safety perceptions and willingness to pay for tested beef. The Australian Journal of Agricultural and Resource Economics 49:197-209.

McFadden, D. (1974). Conditional Logit Analysis of Qualitative Choice Behavior. In P. Zarembka (ed.), Frontiers in Econometrics. New York: Academic, 105-142.

McFadden, D. (1999). Rationality for Economists? Journal of Risk and Uncertainty 19(1):73-105.

Meuwissen, M. P. M., \& van der Lans, I. A. (2005). Trade-offs between consumer concerns: An application for pork supply chains. Food Economics 2:27-34.

Miller, G. Y., \& Unneverhr, L. J. (2001). Characteristics of Consumers Demanding and Their Willingness to Pay for Certified Safer Pork. Journal of Agribusiness 19(2):101-119.

Mitchell, V-W., \& McGoldrick, P.J. (1996). 'Consumers' Risk Reduction Strategies: A Preview and Synthesis', The International Review of Retail, Distribution and Consumer Research, 6(1):133.

Munro, A., \& N. Hanley (1999). Information, Uncertainty, and Contingent Valuation. In I.

Bateman and K. Willis (Eds.), Valuing Environmental Preferences (pp. 258-279), New York: Oxford University Press.

Mørkbak, M., Christensen, T., \& Gyrd-Hansen, D. (2009). Valuation of Food safety in meat - a review of stated preference studies. Food Economics 5(2):63-74

Mørkbak, M. R., Christensen, T., \& Gyrd-Hansen, D. (2010). The importance of food safety as a quality characteristic - a choice experiment. British Food Journal 112(7):775-791.

Mørkbak, M., Christensen, T., \& Gyrd-Hansen, D. (2011). Consumers' willingness to pay for safer meat depends on the risk reduction methods - A Danish case study on Salmonella risk in minced pork. Food Control 22:445-451.

Nakayachi K. (2000). So people actually pursue risk elimination in environmental risk management? Risk Analysis 20:705-11

Nayga, R. M. j., Woodward, R., \& Aiew, W. (2006). Willingness to Pay for Reduced Risk of Foodborne Illness: A Nonhypothetical Field Experiment. Canadian Journal of Agricultural Economics 54:461-475.

Nelson, C. H. (2001). Risk Perception, Behavior, and Consumer Response to Genetically Modified Organisms. American Behavioral Scientist 44(8):1371-1388.

Norinder, A., Hjalte K., \& Persson U. (2001). Scope and scale insensitivities in a contingent valuation study of risk reductions, Health Policy 57:141-153

Rose, J. M., Bliemer, M. C. J., Hensher, D. A., \& Collins, A. T. (2008). Designing efficient stated choice experiments in the presence of reference alternatives. Transportation Research Part B 42:395-406.

Ruby, M. C., Johnson, F. R., \& Mathews, K. E. (1998). Just say no: Opt-out alternatives and anglers' stated preferences. TER General Working Paper No.T-9801R. 
Shogren, J. F., Fox, J. A., Hayes, D. J., \& Roosen, J. (1999). Observed Choices for Food Safety in Retail, Survey, and Auction Markets. American Journal of Agricultural Economics 81(5):11921199.

Siegrist, M. (2008). Factors influencing public acceptance of innovative food technologies and products. Trends in Food Science \& Technology, 19:603-608.

Swait, J., Adamowicz, W. L., Hanemann, M., Diederich, A., Krosnick, J., Layton, D., Provencher, W., Schkade, D., \& Tourangeau, R. (2002). Context Dependence and Aggregation in Disaggregate Choice Analysis. Marketing Letters 13(3):195-205.

Teisl, M.F., \& Roe, B.E. (2010). Consumer willingness-to-pay to reduce the probability of retail foodborne pathogen contamination. Food Policy 35(6):521-530.

Thaler, R. (1980). Toward a Positive Theory of Consumer Choice. Journal of Economic behavior and Organization 1:39-60.

Train, K. (2003). Discrete Choice Methods with Simulation. Cambridge: Cambridge University Press.

Tversky, A., \& Kahneman, D. (1991). Loss aversion in riskless choice: a reference-dependent model. The Quarterly Journal of Economics (November):1039-1061.

Von Neumann, J., \& Morgenstern, O. (1944). Theory of games and economic behaviour. Princeton University Press.

Williams, P. R. D., \& Hammitt, J. K. (2000). A Comparison of Organic and Conventional Fresh Produce Buyers in the Boston Area. Risk Analysis 20(5):735-746.

Wittink, D. R., Krishnarnurthi, L., \& Reibstein, D. J. (1990). The effect of differences in the number of attribute levels on conjoint results. Marketing Letters 1(2):113-123. 